\title{
Phenotypic plasticity in response to soil moisture availability in the clonal plant Eremosparton songoricum (Litv.) Vass.
}

\author{
JianCheng WANG ${ }^{1,2,3}$, Xiang SHI ${ }^{4}$, DaoYuan ZHANG ${ }^{1,2^{*}}$, LinKe $\mathrm{YIN}^{1,2}$ \\ ${ }^{1}$ Key Laboratory of Biogeography and Bioresource in Arid Land, Xinjiang Institute of Ecology and Geography, Chinese \\ Academy of Sciences, Urumqi 830011, China; \\ ${ }^{2}$ Turpan Eremophytes Botanical Garden, Chinese Academy of Sciences, Turpan 838008, China; \\ ${ }^{3}$ Graduate University of Chinese Academy of Sciences, Beijing 100049, China; \\ ${ }^{4}$ Department of Forestry, Shihezi University, Shihezi 832000, China
}

\begin{abstract}
Eremosparton songoricum (Litv.) Vass is a dwarf clonal shrubby legume developed on the windward slopes of mobile or semi-fixed sand dunes of Central Asia. It is assumed that $E$. songoricum must possess a high degree of phenotypic plasticity for such a heterogeneous habitat. The variations of $E$. songoricum plants growing in two typical microhabitats (the upper slope and the lower slope of semi-mobile dune) were investigated. The morphological characteristics and the biomass allocation patterns were measured and compared at the clonal fragment level. Compared with the clonal fragment on the lower slope of dune, the clonal fragment on the upper slope of the dune (a) declined in total biomass and ramet height, (b) increased the length of rhizomes and the number of roots, (c) increased the degree of asymmetry, and (d) heightened allocation to the belowground biomass. Our results confirmed the hypothesis of high phenotypic adjustment capacity of $E$. songoricum to habitat moisture availability. Phenotypic plasticity of $E$. songoricum contributed to reduce the damage risk, led to an environmentally induced specialization in function of resources exploitation, resulted in its persistence in heterogeneous environments and was adaptive in sand dune environment.
\end{abstract}

Keywords: Eremosparton songoricum; moisture availability; phenotypic plasticity; sand dune

\section{Introduction}

Clonal growth allows clonal plant to form a large network consisting of ramets which is located at some distance from each other, and connected by spacer such as stolon or rhizome for a variable period of time. It implies that clonal plants are likely to experience small-scale spatial heterogeneity (Roiloa and Retuerto, 2006), because natural environments are always heterogeneous, and resource acquisition depends on the quality of patches selected for root and shoot placement (Hutchings and Wijesinghe, 2008). Plasticity is one potential strategy of plant to cope with environmental heterogeneity (Poor et al., 2005). Compared with non-clonal plants, the ramets of clonal plants not only react on their surroundings, and also on the environment of connected ramets. As a result, clonal plants have both clonal modularity and organismic modular- ity (Zhu et al., 2007). By regulating their morphology, clonal plants are capable of adapting to various environmental conditions by means of clonal growth strategy (Liu et al., 2004). But, plastic growth would be unnecessary, and even costly, if the resource distribution was temporally unpredictable. As a whole, ramets would be equal in size and evenly distributed, as concentrating biomass in a particular area would be disastrous if the environment suddenly changed (Poor et al., 2005). Thus plasticity is favored when environmental cues are reliable and operate long enough for plants (Lötscher, 2006). This is also the objectives of the habitat adaptation research by which the morphological plasticity to achieve foraging behavior of clonal plants is suitable for the resource status of

Received 2010-06-28, accepted 2010-10-10

doi: 10.3724/SP.J.1227.2011.00034

* Corresponding author: DaoYuan ZHANG (E-mail: daoyuanzhang@163.net) 
habitat (Zhou et al., 2006). Plant populations may show differentiation in phenotypic plasticity, and the hypothesis of habitat adaptation suggestes that greater levels of environmental heterogeneity correspond with the higher magnitudes of phenotypic plasticity (Gianoli and Gonzalez-Teuber, 2005). However, the field evidence for this hypothesis is lacking.

Gurbantunggut Desert is situated in the center of the Junggar Basin in Xinjiang Uygur Autonomous Region of China, and is the second largest desert in China with an area of $48.8 \times 10^{3} \mathrm{~km}^{2}$ (Qian et al., 2002; Chen et al., 2007). Topography in the sand dunes indicates that the distribution of resources is high heterogeneity. Being a dominant plant of sand dune with heterogeneous moisture availability, Eremosparton songoricum (Litv.) Vass. probably has evolved a high capacity for phenotypic plasticity. In this study we aim to explore the morphological responses and biomass allocation patterns within natural populations of $E$. songoricum to different micro-environments in a sand dune. We test the hypothesis that $E$. songoricum must possess a high degree of phenotypic plasticity for such a heterogeneous habitat. We examined the variation of E. songoricum plants growing in two typical microhabitats (the upper slope and the lower slope of a semi-mobile dune). The morphological characteristics and the biomass allocation patterns were measured and compared at the clonal fragment level.

\section{Study area and methods}

\subsection{Study area}

The study site was located on a sand dune $\left(46^{\circ} 28.07^{\prime} \mathrm{N}\right.$, $88^{\circ} 33.07^{\prime} \mathrm{E}$, with a slope of $30^{\circ}$ ) in the Gurbantunggut Desert of Xinjiang, China. The climate of the desert is temperate continental one (Zhang and Chen, 2002; Li et al., 2010), with an annual precipitation of 80-160 $\mathrm{mm}$ and an annual evaporation of 2,000-2,800 $\mathrm{mm}$. The annual average temperature is $5-5.7^{\circ} \mathrm{C}$ (the ex- treme temperatures exceed $-40^{\circ} \mathrm{C}$ and $40^{\circ} \mathrm{C}$, respectively). There are a large number of ephemeral and semi-shrub species in the desert (Qian et al., 2002; Zhang et al., 2010). Due to disturbances of a large number of man-made projects, the fixed dunes were seriously degraded, while mobile sand dunes are widely presented.

\subsection{Plant species}

Eremosparton songoricum (Litv.) Vass. is a dwarf clonal shrubby legume developed on the windward slopes of mobile or semi-fixed sand dunes of Central Asia (Liu, 1987; Zhang and Hai, 2002; Yin et al., 2006; Liu et al., 2010). It has intermediate-size ramets (50-80 cm in height) and wide-spreading clones due to its rhizomatous, guerilla growth form. The aboveground stems of E. songoricum die in winter and sprout new branches from the stems remained from the previous year or from rhizomes. The rhizomes of sprouting branches are normally distributed beneath the soil surface at a depth less than $10 \mathrm{~cm}$ (Zhang et al., 2008) and some stems and roots of sprouting branches die in the initial stage. The leaf has been extremely degraded, which is generally recognized as good and endemic medium in the arid areas.

\subsection{Methods}

A dune with a slope length of about $20 \mathrm{~m}$ was selected in this study in July 2009. No plant grew on the top of the dune. E. songoricum plants developed on the slope of the dune and some plants including Artemisia desertotum, Astragalus grandifous, Astragalus arpilobus, Iris tenuifolia and Soranthus meyeri grew on the bottom of the dune. Sixteen quadrats $(1 \mathrm{~m} \times 1 \mathrm{~m})$ were set on the lower slope of the dune, and other 16 quadrats were set on the upper slope of the dune (Fig. 1). The heights of ramets were recorded in each quadrat. Rhizomes were observed at approximately $6-50 \mathrm{~cm}$ soil depth below the surface, and both ground and underground parts at a depth of $0-50 \mathrm{~cm}$ were

Sand dune

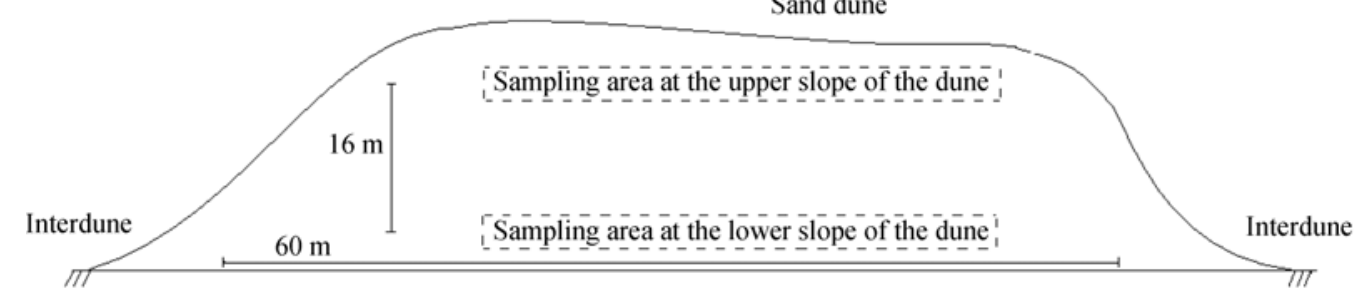

Fig. 1 Schematic diagram of quadrat survey 
harvested in each quadrat. The lengths of rhizomes, the number of ramets, the number of roots, the number of ramets with roots and the number of ramets with fruits in each quadrat were measured. After the harvest, all plant samples were subdivided into roots, rhizomes, branches and fruits, drying up to constant weight at $80^{\circ} \mathrm{C}$ (D'Hertefeldt and van der Putten, 1998). Then, the biomass of the four plant parts belonging to each quadrat was weighted. Soil samples were collected from the depths of $0-10 \mathrm{~cm}, 10-20 \mathrm{~cm}, 20-30 \mathrm{~cm}$, $30-40 \mathrm{~cm}$ and $40-50 \mathrm{~cm}$ in five quadrats. The water contents of soil samples were measured.

\subsection{Analysis}

To test the existence of the phenotypic plasticity in $E$. songoricum for different microenvironments, the following analysis was carried out. Relative parameters were calculated from the data measured in each quadrat and compared between microhabitats. The measurements of soil water contents were repeated 5 times and the measurements of plant characteristic parameters were repeated 16 times. Ramet height was compared using the mean value within quadrat. Data nor- mality was examined with the Kolmogorov-Smirnov test and Shapiro-Wilk W-test. The Levene test was used to examine homogeneity of variance. Independent-Samples $\mathrm{T}$ test was used to analyze differences between the above characteristics of plants that belonged to different geomorphologic position. The statistical package Origin was employed for all above analyses.

\section{Results}

There was a water content gradient at different soil depths (Table 1). Strong evaporation of soil moisture led to the drought of the dune surface. Soil water content was similar in the surface sand layer $(0-10 \mathrm{~cm})$ at the two positions. However, the water content of sand layer $(>10 \mathrm{~cm})$ in the upper slope of the dune was significantly lower than that in the lower slope of the dune $\left(t_{8}=-4.02,-4.59,-2.56\right.$ and -4.03 , respectively).

E. songoricum formed the morphological phenotypic plasticity to adapt the local environment (Fig. 2). The ramet height of $E$. songoricum in the upper slope

Table 1 Comparison of soil water contents at different soil depths between the two positions

\begin{tabular}{|c|c|c|c|c|c|}
\hline \multirow{3}{*}{ Positions } & \multicolumn{5}{|c|}{ Soil depths } \\
\hline & $0-10 \mathrm{~cm}$ & $10-20 \mathrm{~cm}$ & $20-30 \mathrm{~cm}$ & $30-40 \mathrm{~cm}$ & $40-50 \mathrm{~cm}$ \\
\hline & \multicolumn{5}{|c|}{$(\%)$} \\
\hline Upper slope & $0.79 \pm 0.02 \mathrm{a}$ & $0.95 \pm 0.03 \mathrm{a}$ & $1.13 \pm 0.05 \mathrm{a}$ & $1.51 \pm 0.07 \mathrm{a}$ & $1.39 \pm 0.04 \mathrm{a}$ \\
\hline Lower slope & $0.83 \pm 0.03 \mathrm{a}$ & $1.13 \pm 0.03 b$ & $1.53 \pm 0.07 \mathrm{~b}$ & $1.80 \pm 0.09 b$ & $1.88 \pm 0.12 b$ \\
\hline
\end{tabular}

Note: Data represent the mean \pm SE. Means with different letters are significantly different at $P<0.05$ level.
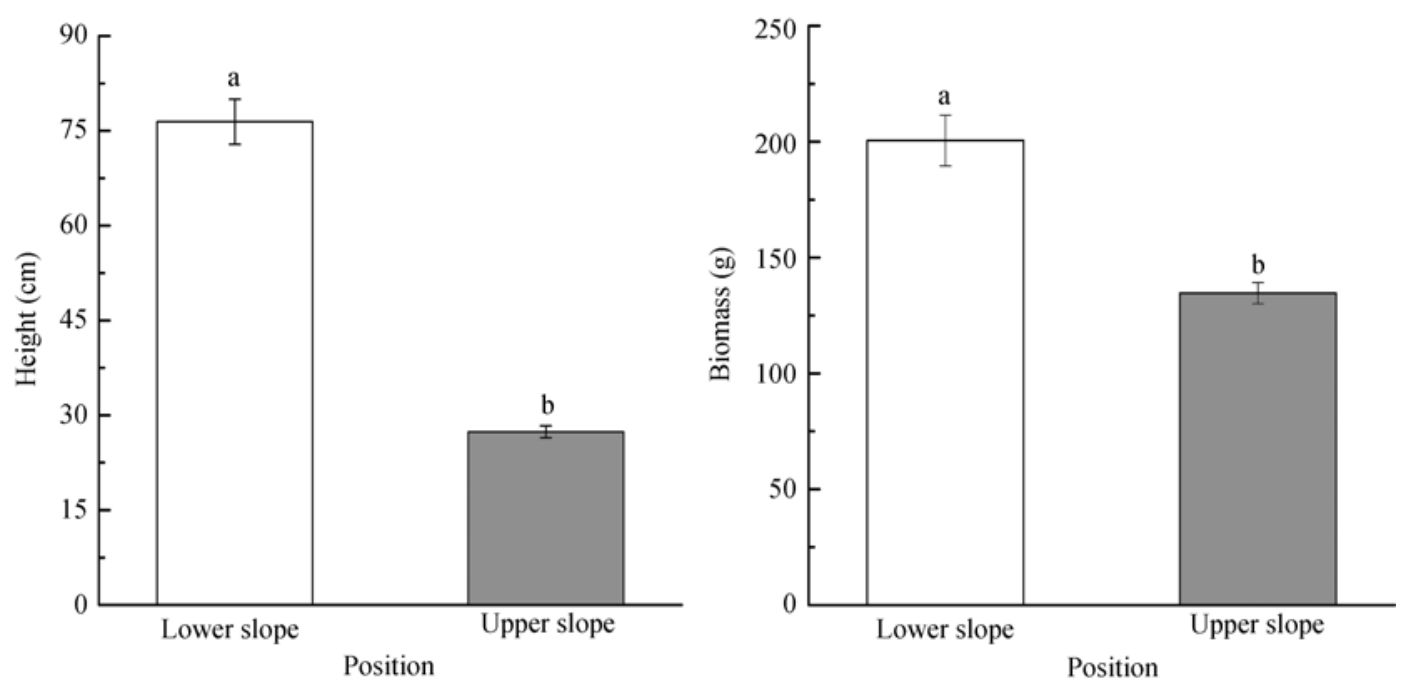

Fig. 2 Comparison of the height and biomass of E. songoricum clonal fragment at the upper slope and lower slope of dune. Different letters above the bars indicate a significant difference at $P<0.05$ level. Vertical bars represent standard errors $(n=16)$ 
of the dune was significantly lower than that in the lower slope $\left(t_{30}=13.27\right)$. A similar trend was found for the weight $\left(t_{30}=5.54\right)$.

There were significant differences in the length of rhizomes and the number of roots between the two positions (Fig. 3). The length of rhizomes and the number of roots in the upper slope of the dune was higher than that in the lower slope of the dune $\left(t_{30}=\right.$ -7.70 and -15.42 ).

Plants growth at the upper slope of the dune showed a certain degree of asymmetry which was significantly high at the upper slope of the dune (Table 2). However, the proportion of ramats with fruit was much lower in upper slope of the dune than that in the lower slope $\left(t_{30}=-28.24\right)$. The ratio of the number of roots with branches to the number of roots and the ratio of the number of ramets with roots to the number of ramets $\left(t_{30}=-8.42\right.$ and -5.32$)$ in the upper and lower slopes of the dune are of a similar trend. The result implies that each ramet needs more roots to supply resources in the upper slope of the dune $\left(t_{30}=3.59\right)$.

The proportion of branch and rhizome weights was affected significantly by the position of the sand dune

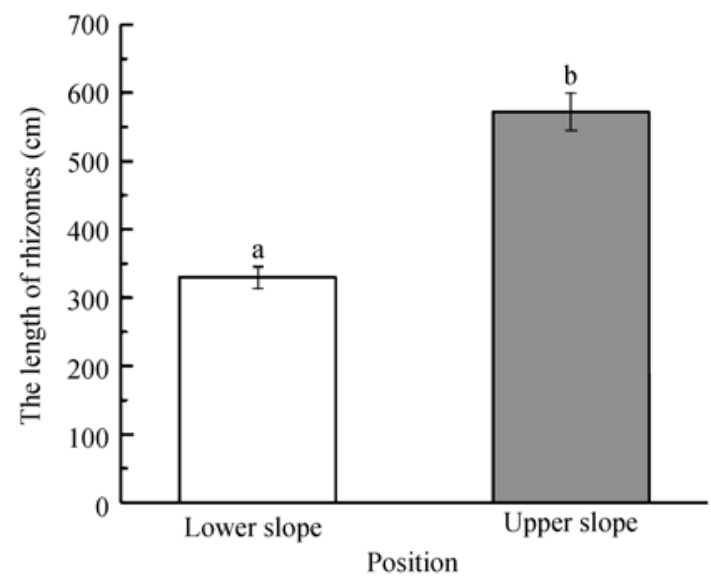

(Fig. 4). Compared with the clonal fragment in the lower slope of dune, the proportion of branch biomass in the upper slope was significantly decreased $\left(t_{30}=\right.$ 6.54). An opposite pattern existed in the proportion of rhizome weight $\left(t_{30}=-8.31\right)$, which displays obvious increment when E. songoricum grew on the barren soils.

\section{Discussion and conclusion}

Water content in desert soil is quite limited (Alamusa et al., 2005), and therefore is an important environmental factor influencing all life functions. We used soil water content as environmental indicator, as shown in Table 1, and found the differences of soil water contents between different dune positions. Plants in low water regime generally had less, smaller, thicker and more pubescent leaves, which reduced evaporative water losses, and smaller shoots and larger roots, which increased biomass allocation to water uptake (Gianoli and Gonzalez-Teuber, 2005). Here the variation in the morphology and biomass partitioning in the response to soil water availability under field

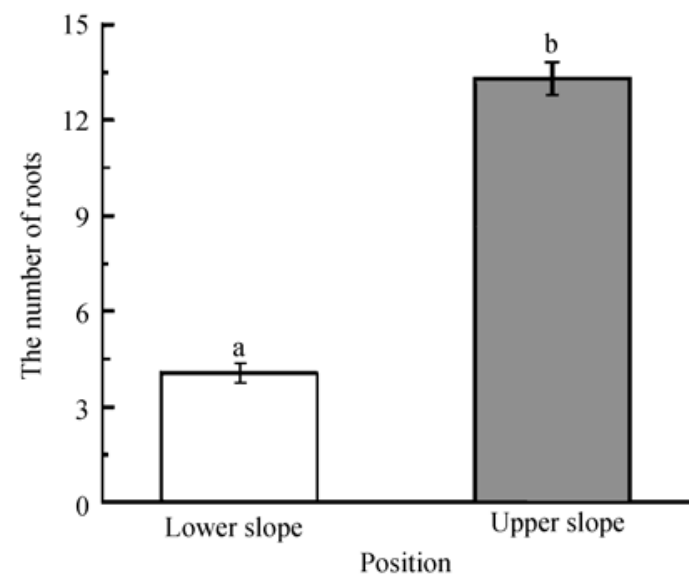

Fig. 3 Comparison of the length of rhizomes and the number of roots of $E$. songoricum clonal fragment at the upper slope and the lower slope of the dune. Different letters above the bars indicate a significant difference at $P<0.05$ level. Vertical bars represent standard errors $(n=16)$

Table 2 Comparison of the asymmetrical degree of E. songoricum clonal fragment at the upper slope and the lower slope of the dune

\begin{tabular}{cccccc}
\hline Traits & Number of ramates & $\begin{array}{c}\text { Number of roots/number } \\
\text { of ramates }\end{array}$ & $\begin{array}{c}\text { Number of roots with } \\
\text { branch/number of roots } \\
(\%)\end{array}$ & $\begin{array}{c}\text { Number of ramates with } \\
\text { root/number of ramates } \\
(\%)\end{array}$ & $\begin{array}{c}\text { Number of ramates with } \\
\text { fruit/number of ramates } \\
(\%)\end{array}$ \\
\hline $\begin{array}{c}\text { Upper } \\
\text { slope }\end{array}$ & $8.06 \pm 0.35 \mathrm{a}$ & $1.69 \pm 0.08 \mathrm{a}$ & $30.5 \pm 1.6 \mathrm{a}$ & $50.2 \pm 2.2 \mathrm{a}$ & $22.4 \pm 2.7 \mathrm{a}$ \\
$\begin{array}{c}\text { Lower } \\
\text { slope }\end{array}$ & $3.50 \pm 0.27 \mathrm{~b}$ & $1.23 \pm 0.10 \mathrm{~b}$ & $64.4 \pm 3.7 \mathrm{~b}$ & $76.1 \pm 4.4 \mathrm{~b}$ & $100.0 \pm 0.0 \mathrm{~b}$ \\
\hline
\end{tabular}

Note: Data represent the mean $\pm \mathrm{SE}$. Means with different letters are significantly different at $P<0.05$ level. 

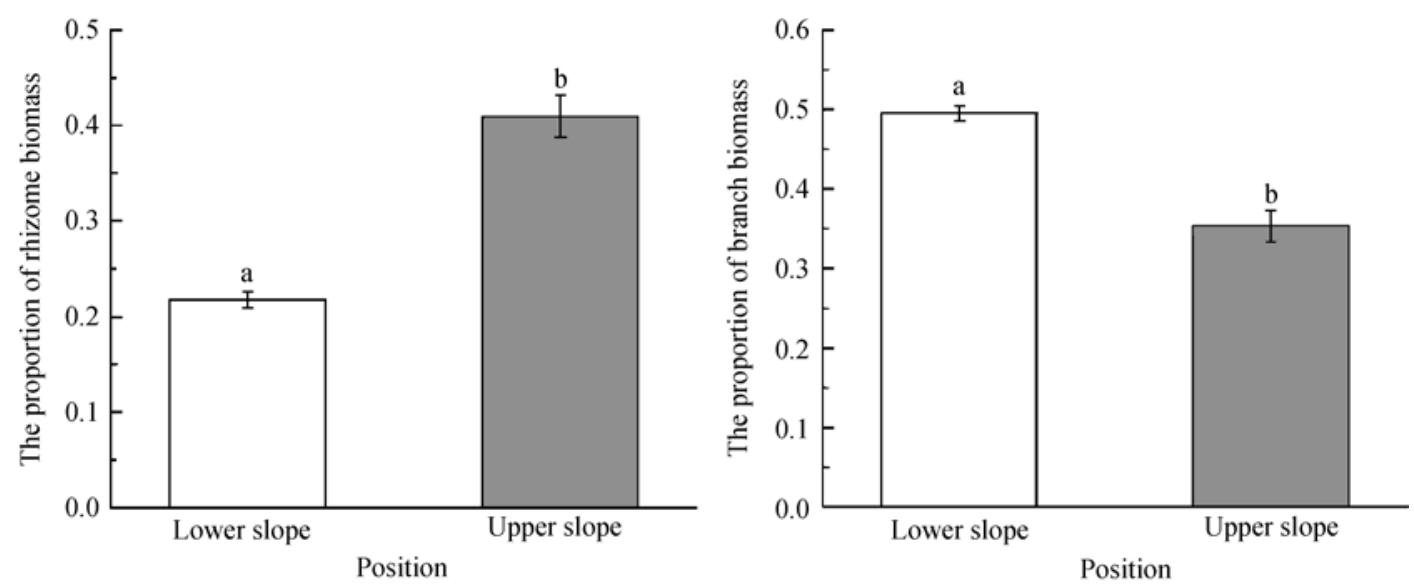

Fig. 4 Comparison of the biomass allocation of E. songoricum clonal fragment at the upper slope and the lower slope of dune. Different letters above the bars indicate a significant difference at $P<0.05$ level. Vertical bars represent standard errors $(n=16)$

conditions was identified. We discussed that, first, how the results matched the proposed hypothesis, and second, what factors influenced the morphologic variation of E. songoricum.

The hypothesis of this study is that sand dune plant E. songoricum must possess a high degree of phenotypic plasticity because its habitat is highly heterogeneous and stable. On the upper slope of the dune, the clonal plants: (a) declined in total biomass and ramet height; (b) increased the length of rhizomes and the number of roots; (c) increased degree of asymmetry, and (d) heightened allocation to the belowground biomass. These evidences clearly confirmed that the stated hypothesis was true.

Many plant species exposed to environmental stresses display plastic responses in their developmental, morphological, physiological, anatomical, or reproductive traits that can support functional adjustments, possibly compensating for the detrimental effect of stress (Sara and Gudrun, 2006). E. songoricum tended to locate plant biomass in protected zones through the production of many small ramets close to the substrate or through higher allocation to the belowground biomass from the lower to the upper slopes of the dune. This difference between different clonal fragments of E. songoricum had the signifi-

\section{References}

Alamusa, Jiang D M, Luo Y M. 2005. Study on soil moisture and water balance in processes of dune fixation shrubs development at semi-arid region. Journal of Soil and Water Conservation, 19: cance in foraging behavior of plant species, for the rhizome played an important role in exploration for new favorable sites (Thomas and Hay, 2008). On the one hand, this variability increased the capacity of absorption resources to improve the viability under adverse conditions. On the other hand, it maximized the effectiveness of the escape strategy. Greater degree of asymmetry in clonal fragment at the upper slope of the dune may result in more efficient absorption of resources through physiological integration and an overall benefit to the plant species (Makihiko et al., 2008).

In conclusion, the results of the present work provide the evidence of the hypothesis of habitat adaptation. Phenotypic plasticity in biomass allocation and morphological traits of E. songoricum contributed to reduce the damage risk, led to an environmentally induced specialization in function of resources exploitation, resulted in its persistence in heterogeneous environments and was adaptive to sand dune environment.

\section{Acknowledgements}

This work was supported by the Key Knowledge Innovation Project of Chinese Academy of Sciences (KSCX2-YW- Z1020), the National Basic Research Program of China (2009CB825104), and the National Natural Science Foundation of China (30970547).

107-110.

Chen R Y, Zhang Y M, Pan B R, et al. 2007. Relation between disturbance and spatial heterogeneity of soil nitration in Gurbantunggut 
Desert. Journal of Desert Research, 27: 257-265.

D'Hertefeldt T, van der Putten W H. 1998. Physiological integration of the clonal plant Carex arenaria and its response to soil-borne pathogens. Oikos, 81: 229-237.

Gianoli E, Gonzalez-Teuber M. 2005. Environmental heterogeneity and population differentiation in plasticity to drought in Convolvulus chilensis (Convolvulaceae). Evolutionary Ecology, 19: 603-613.

Hutchings M J, Wijesinghe D K. 2008. Performance of a clonal species in patchy environments: effects of environmental context on yield at local and whole-plant scales. Evolutionary Ecology, 22: 313-324.

Li C J, Li Y, Ma J, et al. 2010. Spatial heterogeneity of soil chemical properties between Haloxylon persicum and Haloxylon ammodendron populations. Journal of Arid Land, 2: 257-265.

Liu Q, Li Y X, Zhong Z C. 2004. Effects of moisture availability on clonal growth in bamboo Pleioblastus maculata. Plant Ecology, 173: 107-113.

Liu Y, Zhang D Y, Yang H L, et al. 2010. Fine-scale genetic structure of Eremosparton songoricum and implication for conservation. Journal of Arid Land, 2: 26-32.

Liu Y X. 1987. Flora in Desertis Reipublicae Populorum Sinarum. Tomus II. Beijing: Science Press, 174.

Lötscher M. 2006. Resource allocation in clonal plants. Progress in Botany, 67: 536-561.

Makihiko I, Dennis F W, Marinus J A W. 2008. Optimal biomass allocation in heterogeneous environments in a clonal plant-spatial division of labor. Ecological Modelling, 213: 156-164.

Poor A, Hershock C, Rosella K, et al. 2005. Do physiological integration and soil heterogeneity influence the clonal growth and foraging of Schoenoplectus pungens? Plant Ecology, 181: 45-56.

Qian Y B, Lei J Q, Wu Z N. 2002. Vertical distribution of aeolian sandy soil moisture and recovery of damaged vegetation in Gurbantunggut
Desert. Journal of Arid Land Resources and Environment, 16: 69-74.

Roiloa S R, Retuerto R. 2006. Small-scale heterogeneity in soil quality influences photosynthetic efficiency and habitat selection in a clonal plant. Annals of Botany, 98: 1043-1052.

Sara P, Gudrun B. 2006. Phenotypic plasticity and mechanical stress: biomass partitioning and clonal growth of an aquatic plant species. American Journal of Botany, 93: 1090-1099.

Thomas R G, Hay M J M. 2008. Adaptive variation in physiological traits underpinning stem elongation responses among nodally-rooting stoloniferous herbs. Evolutionary Ecology, 22: 369-381.

Yin L K, Tan L X, Wang B. 2006. Rare and Endangered Higher Plants Endemic to Xinjiang. Urumqi: Xinjiang Scientific and Technical Publishing House, 74-75.

Zhang D Y, Ma W B, Shi X, et al. 2008. Distribution and bio-ecological characteristics of Eremosparton songoricum, a rare plant in Gurbantunggut Desert. Journal of Desert Research, 28: 430-436.

Zhang L Y, Chen C D. 2002. On the general characteristics of plant diversity of Gurbantunggut sandy desert. Acta Ecologica Sinica, 22: 1923-1932.

Zhang L Y, Hai Y. 2002. Plant communities excluded in the book of "The Vegetation and Its Utilization in Xijiang" I: The desert plant communities. Arid Land Geography, 25: 84-89.

Zhang Y M, Wu N, Zhang B C, et al. 2010. Species composition, distribution patterns and ecological functions of biological soil crusts in the Gurbantunggut Desert. Journal of Arid Land, 2: 180-189.

Zhou H K, Zhao X Q, Zhou L, et al. 2006. Alpine meadow degradation alter the clonal growing characteristics of Potentilla anserine. Acta Ecologica Sinica, 26: 508-520.

Zhu Z H, Liu J X, Wang X A. 2007. Review of phenotypic plasticity and hierarchical selection in clonal plants. Journal of Plant Ecology, 31: $588-598$. 